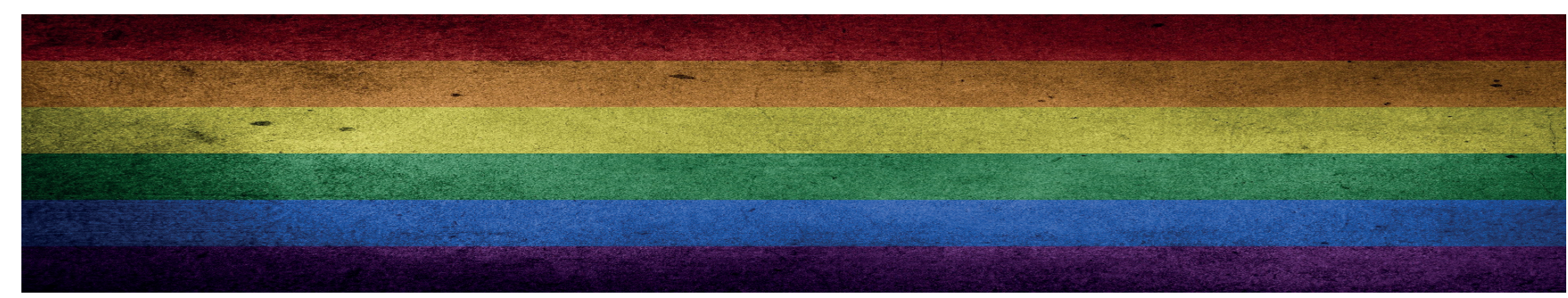

Tomado de: https://pixabay.com/es/illustrations/bandera-lgbt-gay-lgbtq-lesbiana-1184117/

\title{
Tipos de familia de origen de un grupo de transexuales peruanos
}

\section{Family types of origin of a group of Peruvian transsexuals}

\author{
Rosario Yslado-Méndez
}

\section{RESUMEN}

El estudio se enmarca en la línea de investigación de género y cuidados de vida cotidiana y responde a la pregunta ¿Cuáles son los tipos de familias de origen de un grupo de transexuales peruanos?; cuyo objetivo fue analizar los tipos de familia de origen de un grupo de transexuales peruanos. La respuesta se sustenta de una parte en la revisión de la literatura, y de otra en los resultados obtenidos en un estudio exploratorio realizado al respecto. El análisis se ha realizado en base a las referencias conceptuales de diversas teorías, como la teoría de sistemas de Bertalanfly, teoría ecológica de Bronfenbrenner, teorías del desarrollo del aprendizaje social y de la personalidad de Bandura y Walters, teoría cognitva-contextual de Iraurgi, Martínez-Pampliega, Iriarte y Sanz, teoría del apego de Bowlby y teoría de la seguridad emocional de Cummings y Davies. Se concluye que la mayoría de los transexuales peruanos que realizan trámites para el reconocimiento de su identidad ante la Corte Superior de Justicia de Perú, proceden de familias de padres heterosexuales separados/ divorciados y en segundo lugar de familias reconstituidas; pero también los cisexuales tienen tipos familias de origen similares al de los transexuales.

Palabras clave: Familia, transexuales, derechos humanos.

\section{ABSTRACT}

The study is part of the research line on gender and daily life care and answers the question: what are the types of families of origin of a group of Peruvian transsexuals? whose objective was to analyze the types of family of origin of a group of Peruvian transsexuals. The answer is based, partly, on the literature review, and partly on the results obtained in an exploratory study carried on in this regard. The analysis has been based on the conceptual references of various theories, such as Bertalanfly's theory of systems, Bronfenbrenner's ecological theory, Bandura and Walters' theories of the development of social learning and personality, Iraurgi, Martínez-Pampliega, Iriarte and Sanz's, theory cognitive-contextual theory, Bowlby's attachment theory and Cummings and Davies' theory of emotional security. It is concluded that the majority of Peruvian transsexuals who carry out procedures for the recognition of their identity before the Superior Court of Justice of Peru, come from families of separated / divorced heterosexual parents and secondly from reconstituted families; but also cisexuals have family types of origin similar to that of transsexuals.

Keywords: Family, transsexuals, human rights. 


\section{INTRODUCCIÓN}

El presente estudio aborda un tema vigente y polémico, como visibilizar el tipo de familia de origen del cual procede un grupo de dieciséis transexuales peruanos, quienes realizaron un procedimiento judicial para el reconocimiento de la identidad de su género (modificación del nombre y sexo registral), pues en el Perú aún no se aprueba una ley de identidad de género o la vía administrativa para el reconocimiento de las identidades trans* (Zelada, 2017).

Al realizar la revisión biblio y electrográfica (congresos, revistas, libros y web), se ha encontrado estudios previos sobre los siguientes temas: construcción de la identidad en transexuales (Rodríguez y Rodríguez, 2009; Ocampo, Pineda \& Reyes, 2017; Freyre, 2018); construcción de familias diversas (Mejía y Ito, 2015); familias constituidas por parejas transexuales (Platero \& Ortega, 2017; Azkuenaga \& Gandarias, 2019;); dinámica, funcionalidad familiar y trastornos depresivos en transexuales (Ballesteros, Cortés, \& Gacharná, 2016; Villalobos, 2018); percepciones, actitudes y dilemas de los padres y familiares de transexuales (Rocha, 2016); derechos humanos y transexualismo (Prado, 2015; Cotrina, 2018); pero no se encontró reportes de estudios similares al que se presenta en este estudio; por lo tanto los aportes vertidos, de una parte cubren un vacío en el conocimiento referido a la familia de origen de los transexuales, y de otra proporcionan conocimientos para el diseño de políticas públicas de cuidado, salud y educación.

Este trabajo se enmarca en la línea de investigación de género y cuidados de vida cotidiana, y se justifica porque aporta nuevos conocimientos para comprender y explicar un tema poco investigado a nivel nacional y mundial, como los tipos de familia de origen de un grupo no hetero-normativo (transexuales) minoritario, vulnerable, discriminado y estigmatizado, que al igual que el grupo heterosexual tienen los mismos derechos humanos, pero se cuestionan y no se aceptan en diferentes espacios de la comunidad nacional e internacional.
El ensayo responde a la interrogante ¿Cuáles son los tipos de familias de origen de un grupo de transexuales peruanos?; y el análisis se ha realizado en base a las referencias conceptuales de la teoría de sistemas, Bertalanfly (1968), teoría ecológica (Bronfenbrenner, 1979), teorías del desarrollo humano (teoría del aprendizaje social y desarrollo de la personalidad de Bandura \& Walters (1974); teoría cognitva-contextual de Iraurgi, et al. (2011); teoria del apego de Bowlby (1998); y teoría de la seguridad emocional de Cummings \& Davies (2010). De acuerdo con lo expuesto, el objetivo del presente trabajo ha sido: Analizar los tipos de familia de origen de un grupo de transexuales peruanos.

\section{DESARROLLO DEL PROBLEMA DE INVES- TIGACIÓN}

Resulta difícil emitir una respuesta contundente a la interrogante planteada en este ensayo; sin embargo, de modo aproximado se afirma que la mayoría de los transexuales proceden de familias cuyos padres fueron separados o divorciados, con indicios de ser familias disfuncionales. La respuesta se sustenta de una parte en la revisión de la literatura, y de otra en los resultados obtenidos en un estudio exploratorio realizado al respecto. Para comprender la tesis propuesta, es pertinente considerar la teoría referente a la familia, sus funciones, tipos de familia y transexualismo, que se expone en los párrafos siguientes.

\section{Familia y sus funciones}

Etimológicamente el término familia proviene de la raíz latina famulus, que significa "siervo, esclavo doméstico" (Gervilla, 2015); pero con el paso del tiempo el concepto de familia ha experimentado cambios a partir de distintas orientaciones teóricas y disciplinas científicas, y más aún en el contexto actual su concepto ha evolucionado, no se concibe el concepto de familia tradicional, sino de familias con características heterogéneas; por lo tanto resulta difícil asumir un concepto único de familia; sin embargo se acepta que la familia además de promover la procreación, deba asumir roles, costumbres, creencias, valores y otros que establece la so- 
ciedad, que las modifica de acuerdo a las demandas y necesidades del entorno mundial.

La historia de la humanidad es tan antigua como la historia de la familia; desde los orígenes de la humanidad, la familia ha cumplido determinadas funciones básicas para satisfacer las necesidades principales de sus miembros, así como otras funciones que le han delegado histórica y socialmente. La familia es un sistema social que permite la reproducción de la especie, de la cultura y del sistema de relaciones económicas, políticas y sociales de una determinada comunidad, y prepara a sus miembros para convivir adaptativamente en dicha comunidad (Oliva y Villa, 2014; Martínez, 2016). Como factor de protección promueve la intersatisfacción mutua, de las necesidades humanas, materiales y psicológicas de sus miembros, y como factor de riesgo presenta carencias de tipo material, emocional y moral, y no satisface las necesidades primarias y secundarias de sus miembros, no promueve la práctica de valores y de estilos de vida saludables, contrariamente genera conductas inadaptativas, que pueden traducirse en comportamientos problemáticos (Flaquer, 2003).

Existe una vasta bibliografía sobre las diferentes funciones de la familia (Cala, Tamayo, \& Minervy 2013; Oliva y Villa, 2014; Martínez, 2016), y específicamente sobre las funciones del maternaje y paternaje positivos (Macías, 1978), que condicionan las tendencias favorables para el desarrollo integral, de la personalidad e identidad e individualidad de los hijos, que está esencialmente ligada a la identidad familiar; y por el contrario, cuando tales necesidades no son satisfechas suficientemente, se favorecen tendencias negativas para el desarrollo integral, que pueden expresarse como retardo, distorsión o detención del desarrollo y psicopatologías.

\section{Tipos de familia}

En las últimas décadas, la sociedad mundial ha experimentado una serie de trasformaciones que afectan los factores sociales, culturales, políticos, económicos, demográficos, educativos, legales y tecnológicos que interaccionan cons- tantemente con el grupo familiar, afectando su organización, estructura, dinámica y la calidad de las interacciones intrafamiliares, que se relacionan con el desarrollo psicológico de los seres humanos durante el ciclo vital (Arranz, 2004; Navarro, Musitu y Herrero, 2007). Asimismo, las relaciones matrimoniales, las relaciones interpersonales entre los padres e hijos y las actitudes de crianza, de acuerdo con su frecuencia, contenido, intensidad y significatividad, también influyen en diferentes áreas (cognitivo, socioemocional, moral) y etapas del desarrollo psicológico.

De otra parte, en el contexto actual de trasformaciones aceleradas, globalización y de predilección por la innovación, afecta los aspectos demográficos (disminución de familias nucleares, funcionales, menor cantidad de hijos, mayor esperanza de vida de los padres, menos niños y adolescentes porque los adultos tempranos postergan el matrimonio y la procreación o prefieren permanecer solos); y la organización de la familia (aumento de familias separadas/divorciadas, reconstituidas, monoparentales y de uniones no matrimoniales) (Navarro, et al., 2007).

Asimismo, cada familia tiene su propia composición, dinámica, reglas, cultura y economía; por tanto, su concepción es flexible considerando que sus componentes son diversos, como sus integrantes lo deseen y como tal se conciben familias disímiles, amalgamadas con integrantes de iguales o diferentes sexos y géneros, de iguales o diferentes orígenes territoriales, así como de la misma proveniencia biológica o no, unidos formal o informalmente (Oliva y Villa, 2014).

En Latinoamérica y Perú es más frecuente la familia nuclear; así de acuerdo al último censo nacional de población, vivienda y comunidades indígenas realizada en el Perú, la mayoría de las familias de la población peruana son de tipo nuclear (53.9\%), en segunda instancia son hogares sin núcleo (26.9\%), el $20.6 \%$ son familias extendidas, en cuarto lugar (16.8\%) son familias unipersonales, seguido de familias compuestas $(2.5 \%)$ (Instituto Nacional de Estadística 
e Informática [INEI], 2018). Se aclara que los tipos de familias mencionadas no son las únicas que existen en el Perú, también están presentes las familias monoparentales, reconstituidas, de cohabitación, sustitutas, de acogida, subrogada y homoparentales. Asimismo, para el año 2016 a nivel nacional se inscribieron 15 109 divorcios, siendo la Región Lima la que registró mayor número de estos (INEI, 2016).

A continuación, se describe la definición de cada tipo de familia consignado en párrafo anterior, según lo propuesto por el INEI (2018), Navarro, et al. (2007), Palacios (2002) y Sánchez (2019), las cuales fueron elaboradas de acuerdo a la estructura familiar, el parentesco y tipo des relaciones entre los miembros, y se tuvieron en cuenta para realizar el estudio que se describe en este trabajo; tales definiciones son las siguientes:

a) Familia nuclear o elemental: Es la unidad familiar básica, compuesta por el esposo (padre), esposa (madre) e hijos; estos últimos pueden ser de la descendencia biológica de la pareja o hijos adoptados por la familia.

b) Familia extendida o consanguínea: Se compone de más de una unidad nuclear, comprende más de una generación y está basada en los vínculos de sangre de varios miembros, incluyendo a los padres, hijos, abuelos u otros familiares (tíos tías, sobrinos, primos y demás). c) Familia monoparental: Es la familia constituida por un padre o una madre que no vive en pareja; pero vive al menos con un hijo menor de 18 años. Esta puede tener diversos orígenes, ya sea porque el padre o madre son solteros o enviudaron.

d) Familia de padres separados/divorciados: Familia en la que los padres se encuentran separados o divorciados, se niegan a vivir juntos como pareja; y deben seguir cumpliendo su rol de padres ante los hijos, por muy distantes que estos se encuentren; no niegan la paternidad y maternidad.

e) Familia reconstituida: Es la familia que rota después de una separación, divorcio o viudez, se rehace con el padre o madre que tiene a su cargo los hijos y su nuevo cónyuge. f) Familia de cohabitación: Es la pareja que convive, unida por lazos afectivos sin vínculo legal de matrimonio.

g) Familia homoparental: Se caracteriza por tener a dos padres o dos madres (homosexuales), que adoptan a un hijo y conforman un núcleo familiar.

h) Familia unipersonal: Está formado por una persona sola, sin grupo de convivencia alguno.

i) Familia compuesta: Son las constituidas por una familia nuclear o extendida, al que se le agregan otras personas que no están ligadas por lazos de parentesco alguno (excluyendo a trabajadores del servicio doméstico). j) Familia sin núcleo: Conformada por una persona jefe de hogar, sin cónyuge ni hijos pero que vive con otras personas con las que puede o no tener relaciones de parentesco.

Además de los tipos de familias mencionadas, existen otras clasificaciones afines, que explican el desarrollo psicológico sano o perturbado de las personas, este último desde una concepción holística y sistémica, no depende solamente de la familia, sino influyen otras variables congénitas, genéticas y condiciones físicas de cada individuo; pero es innegable que el contexto familiar funcional, es fundamental para el desarrollo positivo de los individuos. Una familia puede ser funcional o disfuncional, según cumpla sus funciones principales y satisfaga de modo adecuado o no las necesidades de sus integrantes, y haga posible o interfiera de modo significativo en la calidad de vida familiar, el ajuste socioemocional y bienestar de sus miembros.

La familia funcional es la que promueve con efectividad el desarrollo integral de sus miembros y cumple sus funciones básicas para satisfacer las necesidades individuales y grupales (Clavijo, 2011). Por su parte la familia disfuncional (estructura y dinámica familiar irregular transitoria o permanente), es la que presenta incapacidad para enfrentar las crisis y cumplir algunas o todas sus funciones básicas de: afecto, comunicación, adaptabilidad, reso- 
lución de problemas, participación y normas de convivencia (Guzmán-Pantoja, et al., 2008); y genera conductas no adaptativas frente a situaciones de estrés. Algunas características de estas familias son: progenitor ausente (separado/divorciado/fallecido), padres en conflicto permanente que inclusive generan violencia intrafamiliar, falta de tiempo compartido, comportamiento sexual anormal o inmoral, silencio encubridor, preferencia o rechazo por alguno de los miembros de la familia, límites inadecuados o inexistentes de control y de respeto (Larroca, 2010; Clavijo, 2011).

Además la familia disfuncional es un factor de riesgo psicológico, que afecta el desarrollo adecuado de los individuos y está asociado significativamente a la presencia de algún trastorno mental en uno o más miembros de la familia; por lo tanto se evidencia algún tipo de desajuste psicosocial, que genera sufrimiento emocional y tensión por la expresión (verbal, gestual y física) frecuente e intensa de diversas emociones, sentimientos y conductas negativas (Dumbar, 1954); aunque San-Martín (2013) refiere que en muchos casos los miembros que generan disfunción familiar, serian normales desde el punto de vista clínico.

\section{Transexualismo}

3.1. Identidad de género

El término identidad proviene del vocablo latín identïtas, que significa grupo de rasgos y características que diferencia a un individuo de otro (AND, huella digital, Documento Nacional de Identidad). En términos generales, la identidad personal, es la característica de una persona que persiste sin cambio esencial, a pesar de los cambios en sus funciones y estructura (Warren, 1977); e implica tener un concepto de uno mismo como ser único y diferente, y esta relacionado con el autoconcepto y autoestima (Navarro, et al., 2007). Por su parte la identidad de género es la percepción y sentimiento de pertenecer a un determinado sexo biológico, sea varón o mujer (Rubio, 2008); pero Gavilán (2018) señala lo contrario que "la identidad sexual y de género de la persona transexual no se define por el sexo biológico, sino por la identidad sexual y de género asumida por sí misma" (p.75).

Castillo (2011) y Rodríguez (2014), sostienen que la identificación con la figura paterna, materna y otras personas del entorno social significativas en la vida de los hijos, cuyos discursos son asumidos y conductas son imitadas, son importantes en la construcción sociocultural de la identidad femenina y masculina, como la persuasión de los medios de comunicación social.

De otra parte, la familia es un contexto de interacción social, en el cual se comparten afectos, protección, ternura, vínculos afectivos, conflictos; se configura el poder, las jerarquías, actitudes, conductas, y otras vivencias, que inciden en el desarrollo integral y en la formación de la identidad de género de los miembros de la familia, en una determinada comunidad. Además la construcción de la propia identidad es un proceso cognitivo-afectivo, que se construye en relación con los otros y su consolidación depende de varios factores como los siguientes: - Relaciones interpersonales (aceptación incondicional, afecto, apoyo, respeto), desde el primer año de vida entre los padres (o quienes tengan el poder en la familia) y el hijo, para establecer un adecuado vínculo afectivo (apego seguro) y seguridad emocional, permite al hijo aceptarse, confiar en sí mismo y en su propia valía, y genera un buen desarrollo afectivo social y adaptación psicosocial (Navarro, et al., 2007). - Calidad de las relaciones matrimoniales, de tipo estable y armónico, sin exposición a estrés, violencia y conflictos matrimoniales no resueltos (Cantón, Cortés, Justicia y Cantón, 2013). - Los estilos de socialización que los padres utilizan para inculcar creencias, costumbres, normas y valores para el control de conducta de sus miembros (Navarro, et al., 2007).

- Los estereotipos individual, familiar y socialmente aprobados para imponer una identidad y un rol sexual diferenciado, así como funciones propias del género femenino y masculino; aunque tanto los varones o mujeres pueden asumir o cuestionar los mandatos asignados 
para su género (Velázquez, 2012).

- Conflictos interpersonales con otros miembros de la familia (hermanos, abuelos, tíos, etc.), grupo de pares y otras personas significativas del entorno social (Raffino, 2019).

- Las estrategias utilizadas para enfrentar las crisis propias de la vida (divorcio de padres, crisis vocacional o profesional, pérdida de un ser querido, cambios de etapa evolutiva, etc.) (Raffino, 2019).

\subsection{Aspectos generales del transexualismo}

La identidad transgénero estuvo presente en diferentes culturas, a lo largo de la historia de la humanidad. Existe varios documentos, relatos míticos o históricos, como alusiones que refieren y sugieren la existencia del transgénero y emergencia posterior del transexualismo (Allen, 2015). Cervantes (2009), señala que el término transexual apareció por primera vez en 1923 en la literatura clínica, y alrededor de los años sesenta se incrementó el interés científico por esta identidad, cuando se publicó el libro "El fenómeno transexual".

La transexualidad es considerada como una disforia de género, que se presenta en niños, adolescentes y adultos, que se caracteriza por una marcada incongruencia entre el sexo que uno siente o expresa y el que se le asigna biológicamente, sea de forma transitoria o permanente (Mejía \& Almanza, 2010; American Psychiatric Association, [APA], 2014). Asimismo, el transexual tiene el deseo de vivir y modificar su cuerpo mediante métodos hormonales o quirúrgicos, para que este sea congruente con el género preferido $\mathrm{y}$ ser aceptado como una persona de género opuesto (Organización Mundial de la salud [OMS], 2004).

Los transexuales buscan cambiar o han cambiado sus caracteres sexuales primarios y/o las características sexuales secundarias a través de intervenciones médicas (hormonas y/o cirugía) para feminizarse o masculinizarse; estas intervenciones, por lo general, son acompañadas de un cambio permanente en el rol de género (Bockting y Keatley, 2012).
De acuerdo a Rubio (2008), los transexuales desde la infancia tienen la convicción de pertenecer al sexo opuesto al que nacieron, se sienten insatisfechos con sus propios caracteres sexuales primarios y secundarios, y tienen un profundo sentido de rechazo y deseo manifiesto de un tratamiento hormonal para suprimir los caracteres sexuales secundarios del sexo original, e inducir al del sexo opuesto de forma completa y rápida. Presentan una identidad mental distinta a su fenotipo genital; son mujeres que se sienten "atrapadas" en cuerpos de hombre, y hombres que se sienten "atrapados" en cuerpos de mujer; sin trastornos psiquiátricos graves que distorsionen la percepción de la realidad, que necesitan ser aceptados social y legalmente en el género elegido; por ende, buscan conseguir la reasignación de sexo opuesto y adaptarse al mismo.

\subsection{Causas y consecuencias del transexualismo} Existen diferentes causas sobre el transexualismo, que aún no se habrían probado científicamente; entre algunas se menciona los siguientes: la influencia hormonal en momentos prenatales; la herencia genética o la existencia de trastornos mentales en los padres (Raquel, 2014); también la influencia de los factores de socialización: familia, pares, escuela, entorno sociocultural (Gavilán, 2018).

En comparación con otros grupos y poblaciones, las personas transexuales, enfrentan diferentes niveles de violencia y en diferentes contextos (familia, sociedad). La base de esta violencia seria la transfobia, que son actitudes y comportamientos individuales y grupales de rechazo, desprecio, desdén y violencia hacia este grupo vulnerable. La transfobia estaría fuertemente ligada a la ignorancia, temores irracionales y sentimientos infundados de amenaza, contra la integridad del agresor y constitución de la familia convencional.

De otra parte, la violencia contra las personas transexuales está extendida en Latinoamérica y el Caribe, como tal las personas transexuales 
viven en un estado continuo de tensión y actitudes defensivas, pues son víctimas de agresión (física, psicológica y sexual), incluso graves por lo cual algunos son derivados a los servicios de urgencias de clínicas y hospitales, que afecta su calidad de vida. Al ser personas violentadas experimenten una profunda conmoción emocional, que debe ser tratada junto con las lesiones físicas, y exposición a infecciones de trasmisión sexual (VIH y otras) (Bockting y Keatley, 2012). Además, en un contexto cotidiano y violento, por ser diferentes a los establecido por el sistema binario y cisexual, están expuestos a ser discriminados en las instituciones educativas, centros laborales y en los servicios de salud, y en casos extremos pueden vivenciar violencia y exclusión social, lo cual afecta la percepción que tienen de sí mismos, estimulando el estigma interno (Sánchez, 2006; Salazar, Villayzan, Silva y Caceres, 2010).

\section{Estudio exploratorio sobre tipos de familia de origen de transexuales}

Se realizó un estudio de tipo básico, exploratorio, de diseño transversal, cuyo objetivo fue describir los tipos de familia de transexuales peruanos. Participaron 16 transexuales peruanos, más de la mitad (56.0 \%) fueron mujeres; en mayor porcentaje $(56.0 \%$ ) han sido de las edades de 19 a 29 años; todos fueron solteros (100.0\%); el $6.0 \%$ solo estudiaba, otro $6.0 \%$ estudiaba y trabajaba, el $18.0 \%$ fueron profesionales y el $70.0 \%$ ejercían ocupaciones técnicas, de comercio y no universitarias.

La selección de los participantes fue intencional, y los criterios de inclusión fueron los siguientes: identificarse como transexual y estar tramitando el cambio de su nombre en el Documento de Identidad Nacional (DNI), en una Corte Superior de Justicia (Perú). Se utilizó la técnica de entrevista estructurada, que fue aplicada de forma individual. El trabajo de campo se realizó entre los meses de mayo de 2018 y julio 2019. Las entrevistas fueron transcritas y analizadas mediante el método de análisis de contenido.

Con respecto a los resultados, se encontró que la mayoría (44.0 \%) de familias de los transexuales (varones y mujeres), fueron de padres separados/divorciados. El $25.0 \%$ fueron familias reconstituidas (uno o ambos padres después de separaciones o divorcios volvieron a vivir con otra pareja o cónyuge y sus hijos); seguido de un porcentaje similar para las familias de tipo monoparental (12.5\%) y extendida $(12.5 \%)$, solo una familia fue nuclear (6.0 $\%)$; no se observaron otros tipos de familias. El análisis de los resultados mostrados se realiza desde diferentes puntos de vista. Así, el mayor porcentaje de las familias de origen de los transexuales fueron de padres heterosexuales divorciados, lo cual puede ser por los cambios demográficos actuales que se presentan en el Perú, como la reducción de las familias nucleares y el incremento de otros tipos de familias como de padres divorciados (INEI, 2016). Este resultado es preocupante porque los conflictos matrimoniales previos a la separación o divorcio, indistintamente en familias de padres heterosexuales u homoparentales, pueden generar una dinámica relacional disfuncional de la familia, que afecta el desarrollo socioemocional y adaptación de los hijos (Larroca, 2010; Clavijo, 2011; Cantón, et al., 2013; Talarn, Sáinz y Rigat, 2013).

En una sociedad predominantemente binaria y cisexista, como Perú, el hecho que un hijo visibilice su transexualidad desde la primera infancia dentro de una familia convencional ya es motivo de conflicto y tensión familiar, pues muchos padres no están educados, ni preparados para aceptar la diversidad sexogenérica, lo cual aunado a la crisis matrimonial de los padres (que posteriormente resuelven con separación o divorcio), afecta doblemente la salud mental y sexual del hijo transexual. Entonces cuando se evalúa la salud mental de los transexuales y presenta determinadas psicopatologías (depresión, ansiedad, etc.), resulta difícil afirmar que éstas constituyan parte del perfil psicológico del transexual, pues puede ser efecto de las vivencias negativas en una familia disfuncional y en una sociedad peruana en la que predomina la discriminación de género (Anderson, 2017), que asociado a la opresión y ex- 
clusión social enferma a las personas transexuales (Planella y Pié, 2017; Gavilán, 2018).

Asimismo, es pertinente tener en cuenta que la cuarta parte de las familias de origen de los transexuales participantes en este estudio, fueron inestables estructuralmente, pues han experimentado varias transformaciones, inicialmente fueron nucleares después se tornó de padres separados o divorciados y finalmente fueron reconstituidas, lo cual puede afectar la parentalidad positiva, constituyendo un factor de riesgo para el adecuado desarrollo psicosocial y buena salud mental. Aunque Talarn, et al. (2013) refiere que lo más relevante de una familia de origen, no es su composición, ni la orientación sexual de los progenitores, ni los hijos engendrados con ayuda de la biotecnología, sino que la familia acepte, acoja y trate bien a los hijos, sea cual fuere su identidad de género.

De otra parte, no existe consenso en la comunidad científica, ni suficiente conocimiento científico o teorías sólidas sobre la formación de la identidad de género de los transexuales; aunque existen algunos modelos médicos-biologistas y socioculturales, que explican al respecto; pero aún no son del todo convincentes. Sin embargo, de acuerdo a las teorías psicológicas del desarrollo humano y otras señaladas en la introducción del presente ensayo, se infiere que además de los factores biopsicosociales, la familia (que cumple funciones específicas; inculca roles, estereotipos, relaciones, estilos de socialización, etc.), es el principal factor de socialización para la construcción de la identidad de género, que puede ser femenino, masculino o de tipo mixto (predomina lo genérico sobre lo genético) (Salama, 2012; Gavilán, 2018).

\section{CONCLUSIONES}

En conclusión, la mayoría de los transexuales peruanos que realizan trámites para el reconocimiento de su identidad ante la Corte Superior de Justicia de Perú, proceden de familias de padres heterosexuales separados/ divorciados y en segundo lugar de familias reconstituidas; pero también los cisexuales tienen tipos de familias de origen similares al de los transexuales.

Se recomienda seguir realizando investigaciones cuanti-cualitativas interdisciplinarias transversales (comparativas, correlacionales) y longitudinales, sobre la construcción de la identidad (femenina, masculina y transexual), y la configuración familiar de grupos heteronormativos y no heteronormativos, y acerca de las variables principales y moderadoras que inciden en el origen y desarrollo del transexualismo; pues aún hay muchas interrogantes que resolver (¿en las familias no disfuncionales hay miembros no heteronormativos?; ¿la identidad de género es cambiante o permanente?, ¿el transexualismo es un estilo de vida o una psicopatología?, etc.), para comprender con objetividad y profundidad el transexualismo visible en el contexto peruano, y confirmar teorías científicas al respecto.

Asimismo, el Estado Peruano ha obligado a promover los derechos humanos, a través de sus ministerios competentes, debe generar estrategias para que se cumplan las políticas a favor de los grupos de especial protección, como los transexuales; e implementar tanto políticas públicas de cuidado, para reducir todas las formas de discriminación de los transexuales dentro de la familia, escuela, universidad, centro de trabajo y sociedad en general, como políticas públicas con perspectiva de familia, en un contexto de diversidad sexual, para fortalecer el desarrollo de la familia y de sus miembros, en base a la práctica de valores, el respeto de los derechos fundamentales, la práctica de relaciones armoniosas y equitativas entre sus miembros; y proteger especialmente a las familias en riesgo psicosocial (de padres separados o divorciados, reconstituidas y monoparentales). Finalmente sería pertinente que los organismos internacionales como las Naciones Unidas, que orienta las políticas públicas para el desarrollo sostenible de los países, en la presente década debe fortalecer las políticas orientadas a la igualdad e inclusión de género no heteronormativo. 


\section{REFERENCIAS}

Allen, M. (2015). La transexualidad y la identidad de género a través de la historia. Recuperado de https://transexualesatc.wordpress.com/2015/05/30/ la-transexualidad-y-la-identidad-de-genero-a-traves-de-la-historia/

APA, American Psychiatric Association (2014). Guía de consulta de los criterios diagnósticos del DSM5. Washington, DC: Autor.

Anderson J. (2017). Derechos civiles y discriminación: Balance de investigación en políticas públicas 2011-2016 y agenda de investigación 2017-2021. Perú: Consorcio de investigación económica y social.

Arranz, E. (2004). Familia y desarrollo psicológico. Madrid: Pearson Educación S.A.

Azkuenaga, D. y Gandarias, I. (2019). Un acercamiento a las familias trans*: experiencias y significados de la transparentalidad. Encrucijadas. Revista Crítica de Ciencias Sociales, 17, 1-19.

Ballesteros, I., Cortés, M., \& Gacharná, N. (2016). Estudio de casos de las dinámicas y roles de tres familias con diversidad sexual transexual del centro de atención integral a la diversidad sexual y de género Sebastián Romero (Tesis de Grado). Universidad de la Salle, Colombia.

Bandura, A., \& Walters, R. (1974). Aprendizaje social y desarrollo de la personalidad. Alianza Universidad. Recuperado de http://www.soyanalistaconductual. org/aprendizaje _social_desarrollo_de_la_personaliad_albert_bandura_richard_h_walters.pdf.

Bertalanfly, L.V. (1968). Systems theory: foundations, development, applications. New York: Braziller.

Bockting,W. y Keatley, J. (2012). Por la salud de las personas trans. Estados Unidos de Norteamerica: Organización Panamericana de la Salud.

Bowlby, J. (1998). El apego". Tomo 1 de la trilogía "El apego y la pérdida". Barcelona: Paidós.

Bronfenbrenner, U. (1979). The ecology of human development. Cambridge: Harvard University Press.

Cala, M., Tamayo, M., \& Minervy, M. (2013). Funciones básicas de la familia. Reflexiones para la orientación psicológica educativa. EduSol, 13(44), 60-71.

Cantón, J., Cortés, R., Justicia, Ma., D. y Cantón, D. (2013). Violencia doméstica, divorcio y adaptación psicológica. De la disarmonía familiar al desarrollo de los hijos. España: Ediciones Pirámide.

Castillo, F. (2011). La construcción de la identidad masculina. Argentina: Grupo Editorial Lumen.

Cervantes, I. (2009). Transexualidad. Una perspectiva transdisciplinaria. México: Alfil.

Clavijo, A. (2011). Crisis, familia y psicoterapia. La
Habana: Editorial Ciencias Médicas.

Cotrina, C. (2018). Derechos fundamentales y otros derechos que afectan a lesbianas, gays, bisexuales y personas trans, al negarse la union civil en el Perú (Tesis de Licenciatura). Universidad privada San Juan Bautista, Perú.

Cummings, E. M., \& Davies, P. T. (2010). Marital conflict and children: An emotional security perspec-

tive. Nueva York: Guilflord Press.

Dumbar, F. (1954). Emotions and bodily changes (4a ed.). New York: Columbia University Press.

Flaquer, L. (2003). Las nuevas estructuras familiares. Madrid: La factoría.

Freyre, L. (2018). Construcción de la feminidad en un grupo de mujeres trans de Lima (Tesis

de Licenciatura). Pontificia Universidad Católica del Perú, Perú.

Gavilán, J. (2018). Infancia y transexualidad. España: Ediciones Mágina.

Gervilla, A. (2015). Familia y educación familiar. Conceptos clave, situación actual y valores. España: NARCEA.

Guzmán-Pantoja, J., Barajas-Mendoza, E., Luce-González, E., Valadez-Toscano, F., Gutiérrez-Román E. y Robles-Romero, M. (2008). Disfunción familiar en pacientes pediátricos con asma. Atención primaria, 40, 543-548. Recuperado de https://www. redalyc.org/pdf/167/16720051032.pdf

INEI, Instituto Nacional de Estadística e Informática (2016). Más de 94 mil matrimonios se celebraron a nivel nacional en el año 2016. Recuperado de https:// www.inei.gob.pe/prensa/noticias/mas-de-94-milmatrimonios-se-celebraron-a-nivel-nacional-en-elano-2016-10559/

INEI, Instituto Nacional de Estadística e Informática (2018). Perú: Perfil sociodemográfico. Informe Nacional. Censos Nacionales 2017: XII de Población, VII de Vivienda y III de Comunidades Indígenas. Perú: Autor.

Iraurgi, I., Martínez-Pampliega, A., Iriarte, L. y Sanz, M. (2011). Modelo cognitivo-contextual del conflicto interparental y la adaptación de los hijos, Anales de Psicología, 27(2), 562-573.

Larroca, F. (2010). La familia disfuncional, la dinamia de los grupos y sus aplicaciones prácticas. Recuperado de https://www.monografias.com/trabajos48/ familia-disfuncional/familia-disfuncional.shtml

Macías, R. (1978). Psicoterapia de Familia. Cursos Internacionales OPS-MINSAP-Sociedad Cubana de Psiquiatría. La Habana, 1978-1989.

Martínez, A. (2016). La familia y sus funciones como célula fundamental de la sociedad. Revista Mé- 
dica Electrónica 38(3). Recuperado de http://www. revmedicaelectronica. sld.cu/index.php/rme/article/ view/1831/html_130.

Mejía, J. y Almanza, M. (2010). LGBT Community: History and legal recognitions. Revista Justicia, 17, 78-110. Recuperado de http://publicaciones.unisimonbolivar.edu.co/rdigital/ojs/index.php/justicia/ article/viewFile/671/673.

Mejia, M. y Ito, M. (2015). Dos formas de hacer familia: visibilizando a las Familias Trans. Alternativas en Psicologia, 160-173. Recuperado de https:// www.alternativasnnnnnnn.mnumeros/22-numero-33-agosto-2015-enero-2016/107-dos-formasde-hacer-familia-visibilizando-a-las-familias-trans

Navarro, I., Musito, G. y Herrero, J. (2007). Familias y problemas. España: Editorial Síntesis.

Oliva, E. y Villa, V. (2014). Hacia un concepto interdisciplinario de la familia en la globalización. Justicia Juris, 10(1), 11-20.

Ocampo, Y., Pineda, P. y Reyes, Y. (2017). Construcción de identidad de dos mujeres transgénero comprendida desde la noción del vínculo a la luz del desarrollo humano (Tesis de Grado). Universidad Santo Tomás, Bogotá.

OMS, Organización Mundial de la Salud (2004). Guía de bolsillo de la clasificación CIE-10. Clasificación de los trastornos mentales y del comportamiento. Con glosario y criterios diagnósticos de investigación. CIE10: CDI 10. Madrid: Editorial Médica Panamericana.

Palacios, J. (2002). Familia y desarrrollo humano. España: Alianza Editorial.

Planella, J. y Pié, A. (2017). Pedagogías Transgénero. Colombia: Editorial UOC.

Platero, L. y Ortega, E. (2017) Investigación sociológica sobre las personas transexuales y sus experiencias familiares. España: Transexualia AET.

Prado, D. (2015). Trans el muro: mujeres trans en condiciones inframurales en colombia. Una perspectiva desde los principios de igualdad y no discriminación (Tesis de maestría en Derecho). Pontifica Católica del Perú, Perú.

Raffino, M. (2019). La identidad. Recuperado de https://concepto.de/que-es-identidad/.

Raquel, L. (2014). Transexualidades. Bogotá: Bellaterra S.L.

Rocha, C. (2015). Familias y Diversidad Sexual: Sistematización de la Reunión Satelital realizada en el marco del IV Encuentro Universitario de Género, Salud y Derechos Sexuales y Reproductivos. Nuevo reto para la investigación y las políticas públicas. Recuperado de http://www.codajic.org/sites/www.codajic.org/files/Familias\%20y\%20diversidad\%20sexual\%20Uru- guay\%202015\%20.pdf.

Rodríguez, J. (2014). La psique de Isis. Construcción social de la identidadfemenina. México: Manual Moderno.

Rodríguez, A. y Rodríguez, R. (2009). Familia y Personas Transexuales: una relación al desnudo. Revista sexología y sociedad, 15(40). Recuperado de: https://docplayer.es/93776393-Familia-y-personas-transexuales.html.

Rodríguez, A. y Rodríguez, R. (2009). Familia y Personas Transexuales: una relación al desnudo. Revista sexología y sociedad, 15(40). Recuperado de: https:/docplayer.es/

93776393-Familia-y-personas-transexuales. html.

Rubio, F. (2008). El tercer género ?: La transexualidad. Nómadas. Critical Journal of Social and Juridical Sciences, 17(1), 47-53.

Salama, H. (2012). ¿̇Por qué somos como somos? México: Alfaomega.

Salazar, X., Villayzan, J., Silva, A. y Caceres, C. (2010). Las personas trans y la epidemia del VIH/ sida en el Perú. Aspectos sociales y epidemiológicos. Lima: Lance gráfico.

Sánchez, C. (2006). Violencia física y construcción de identidades. Propuesta de reflexión crítica para las escuelas infantiles. Colombia: Cooperativa Editorial Magisterio.

Sánchez, E. (2019). Los 11 tipos de familia que hay en la actualidad. Recuperado de https://lamenteesmaravillosa.com/los-11-tipos-de-familia-que-hayen-la-actualidad/.

San-Martín, J. (2013). La violencia y sus claves ( $6^{a}$ ed.). España: Ariel Quintaesencia.

Talarn, A., Sáinz, F. y Rigat, A. (2013). Relaciones, vivencias y psicopatología. Las bases relacionales del sufrimiento mental excesivo. España: Herder Editorial.

Velázquez, S. (2012). Violencias y familias. Implicancias del trabajo profesional: el cuidado de quienes cuidan. Buenos Aires: Paídos SAICF.

Villalobos, F. (2018). Relación entre funcionalidad familiar y trastornos depresivos en trans masculinos, Lima-2018 (Tesis de Licenciatura). Universidad César Vallejo, Perú.

Warren, H. (1977). Diccionario de Psicología. México: Fondo de Cultura Económica.

Zelada, C. (2017). Los estándares internacionales para el reconocimiento de las identidades Trans. Lima: Alpamayo S.R.L. 